\title{
4
}

\section{Preço de hortaliças orgânicas segundo canal de comercialização}

\author{
Rafael Rioja Arantes ${ }^{1}$ e Elisabetta Recine ${ }^{2}$
}

O estudo comparou os preços de hortaliças provenientes de sistemas de produção orgânica e convencional em quatro canais de abastecimento com características distintas em Brasília - DF. Os preços de até 25 alimentos foram coletados em dois períodos, novembro de 2015 e abril de 2016, nos seguintes locais: três feiras ecológicas "de rua", galpão da agricultura familiar e Mercado Orgânico, ambos localizados na Central de Abastecimento (CEASA DF) e em três grandes supermercados concorrentes. As análises verificaram as diferenças absoluta e relativa de preços dos orgânicos entre si, e dos orgânicos com os convencionais dos supermercados, sendo que o número de alimentos comparados variou de acordo com a disponibilidade nos canais. Foi constatado que hortaliças orgânicas comercializadas em supermercados chegam a custar mais que o triplo do preço em relação às orgânicas de canais alternativos, e que uma cesta contendo os 16 alimentos pesquisados, chegou a custar mais que o dobro nos supermercados. No comparativo geral com as convencionais, ainda que estas custem mais barato, as orgânicas apresentaram preços competitivos e inclusive menores dependendo do canal. O estudo indica que são incompletas as afirmações e a divulgação de informações relativas aos preços de alimentos orgânicos que não considerem a pluralidade dos canais de abastecimento.

Palavras-chave: segurança alimentar e nutricional, abastecimento, alimentos orgânicos, preços.

\section{Price of organic vegetables according to supply chains}

The present study compared prices between vegetables produced within organic and conventional systems in different food supply chains at the Federal District - DF, Brazil. Prices of 25 vegetables were acquired during field study, which was conducted in November 2015 and April 2016 in the following locations: organic street markets, market exclusive to family farmers and another exclusive to organic food located in the Brazilian Centre of Food Supply (CEASA - DF), and three supermarkets. The data analyses considered absolute and relative price differences of organics among themselves and between the conventionally grown from supermakets. The number of vegetables compared varied according to availability at each supplier. It is shown that organic food sold at supermarkets is substantially more expensive than the organics commercialized in alternative food supply chains. In the comparison among conventional vegetables, even though these are generally cheaper, the organics displayed competitive prices and can cost less depending on the food supply chain. The study concluded that the affirmation and spread of information that do not consider the multiplicity of food supply chains that sell organic food is inaccurate.

Keywords: food security and nutrition, food supply, organic food, prices.

\footnotetext{
${ }^{1}$ Nutricionista e pesquisador do Observatório de Políticas de Segurança Alimentar e Nutrição, Universidade de Brasília - OPSAN/UnB. Endereço para correspondência: Rua Caiubi, 321 apto. 73, CEP: 05010-000, São Paulo - SP. Tel.: (11) 97161-0868. E-mail: rafaelrioja@gmail.com

2 Docente do Departameto de Nutrição Faculdade de Ciências da Saúde Universidade de Brasília. Endereço para correspondência: Campus Darcy Ribeiro, Prédio do Núcleo de Nutrição e Medicina Tropical, Sala 09 (OPSAN/UnB). CEP: 70910-900 - Brasíli-DF. E-mail: recine@unb.br
} 


\section{INTRODUÇÃO E OBJETIVOS}

A produção de alimentos orgânicos tem aumentado globalmente nas últimas décadas tanto em área cultivada quanto em número de países praticantes. O relatório de 2016 da Federação Internacional de Movimentos de Agricultura Orgânica (IFOAM) revela que 50,9 milhões de hectares são destinados à produção neste sistema abrangendo 179 nações. Em 1999, a área em hectares era quase 5 vezes menor, 11 milhões, e menos da metade dos países, 86 , praticavam atividades de produção orgânica ${ }^{[1]}$.

No cenário internacional, a Índia possui o maior número de produtores orgânicos, 585 mil, o que representa $24 \%$ dos 2,4 milhões de produtores no mundo, e a Austrália, a maior área de agricultura orgânica, 22,7 milhões de hectares representando 44\% da área de produção orgânica global. Em relação ao mercado de alimentos, os Estados Unidos da América movimentam $\$ 39,7$ bilhões de dólares, equivalente a $48 \%$ dos 81,6 bilhões do mercado global, enquanto a Súça tem o maior consumo per capita (\$291 dólares) sendo mais de vinte vezes superior à média global de $\$ 11,1$ dólares ${ }^{[1]}$.

O Brasil segue a tendência de crescimento territorial e de produtores inseridos no sistema orgânico. Em 2001, foram sistematizados em maior detalhe os primeiros dados nacionais sobre este tipo de produção. A área com atividade orgânica ocupava cerca de 270 mil hectares com aproximadamente $7 \mathrm{mil}$ produtores certificados ou em processo de certificação[2].

De acordo com o Ministério da Agricultura, Pecuária e Abastecimento (MAPA), a área total destinada à produção orgânica em 2016 alcançou 750 mil hectares ${ }^{[3]}$ e aproximadamente 17 mil produtores registrados no Cadastro Nacional de Produtores Orgânicos (CNPO). Em 15 anos, o número de hectares para produção e produtores orgânicos cresceu $214 \%$ e $142 \%$, respectivamente. Estima-se que do total de produtores, $75 \%$ são agricultores familiares $\mathrm{em}$ transição agroecológica apoiados pelo Plano Nacional de Produção Orgânica e Agroecológica (PLANAPO) implementado a partir da estruturação da Política
Nacional de Produção Orgânica e Agroecológica (PNAPO) $)^{[4,5] \text {. }}$

Desde 1930, diferentes autores têm contribuído para a construção do conhecimento e entendimento da agroecologia como solução aos desafios dos sistemas agroalimentares. A partir dos anos 80, dimensões ambientais, sociais, econômicas, éticas e noções de desenvolvimento foram progressivamente incorporadas ao conceito incialmente focado na produção[6]. A Associação Brasileira de Agroecologia $(\mathrm{ABA})$ a define enquanto: "ciência, movimento político e prática social, portadora de um enfoque científico, teórico, prático e metodológico que articula diferentes áreas do conhecimento de forma transdisciplinar e sistêmica, orientada a desenvolver sistemas agroalimentares sustentáveis em todas as suas dimensões"'[].

O sistema de produção orgânica no Brasil é definido pela Lei no 10.831 de dezembro de 2003 e regulamentado por meio do Decreto no 6.323 de dezembro de 2007 que acrescenta dispositivos sobre a certificação da produção, área explorada, culturas cultivadas e produtividade[ ${ }^{[8]}$.

Lei no $10.831 / 2003[9]$

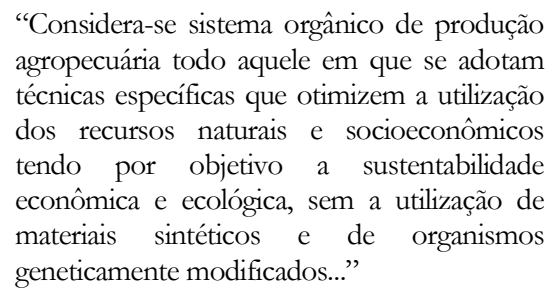

No Distrito Federal (DF), a área produtiva orgânica ocupa 775 hectares, o que corresponde a aproximadamente $10 \%$ do total de terras destinadas a produção orgânica no Brasil, e possuí 110 produtores cadastrados, menos de $1 \%$ dos números nacionais. Do total de produtores orgânicos do DF, 58,2\% (64 produtores) são agricultores familiares em transição agroecológica que comercializam seus alimentos por meio do Controle Social para Venda Direta sem Certificação[10]. Estima-se que 40 mil pessoas, menos de $2 \%$ da população do DF, consomem alimentos orgânicos com frequência semanal[10,11]. 
Levando-se em consideração dados específicos sobre hortaliças orgânicas e agroecológicas no ano de 2010, disponibilizados pela Empresa de Assistência Técnica e Extensão Rural/EMATER -DF, a área cultivada representou 143 hectares com uma produção de 3.900 toneladas. No mesmo ano, o cultivo de hortaliças convencionais abrangeu uma área de 7.136 hectares produzindo 215.300 toneladas ${ }^{[12]}$. Estima-se com base no referido ano, que a produção orgânica de hortaliças foi capaz de suprir $1,7 \%$ da demanda total por hortaliças no Distrito Federal.

Os incentivos resultantes da estruturação de Políticas Públicas e planos alinhados com a produção orgânica e agroecológica, como a PNAPO e o PLANAPO, se apresentam como alternativa contrahegemônica face ao modelo do agronegócio[4,5]. O Brasil é desde 2008, ao ultrapassar os Estados Unidos da América, o maior consumidor de agrotóxicos do mundo, tendo aplicado 852,8 milhões de litros nas lavouras no ano de 2011[13]. Apesar deste número representar os agrotóxicos permitidos conforme a legislação brasileira, 14 produtos estão sendo revisados pela Anvisa em relação aos aspectos toxicológicos e 4 já foram banidos ${ }^{[13]}$.

Os agravos gerados pelo modelo do agronegócio centrado no uso intensivo de insumos químicos e monoculturas agrícolas têm reflexos nas dimensões de saúde humana e socioambientais. $\mathrm{O}$ Programa de Análise de Resíduos de Agrotóxicos em Alimentos (PARA) de 2016 constatou que 19,7\% das amostras estavam insatisfatórias. Elas apresentaram resíduos de agrotóxicos não autorizados para cultura ou estavam acima do Limite Máximo de Resíduos (LMR), estabelecido pela Anvisa. Foram consideradas satisfatórias $80,3 \%$ das amostras, sendo que neste grupo, $42 \%$ das amostras não apresentaram resíduos enquanto $38 \%$ apresentaram resíduos, porém dentro do LMR. Em 1\% das amostras foi detectado risco de intoxicação aguda[14].

Deve-se também considerar a possibilidade de intoxicação crônica, desenvolvida no longo prazo de exposição aos resíduos de agrotóxicos. Os testes para os Limites são baseados no efeito de apenas um ingrediente ativo (IA) do agrotóxico isoladamente. No entanto, os efeitos são pouco previsíveis quando um mesmo IA se acumula ou é combinado com a exposição a outros IA [14]. Em 2017, o Greenpeace realizou testes toxicológicos em alimentos coletados em Brasília e São Paulo, e encontrou resíduos de agrotóxicos em $60 \%$ das amostras, considerando $36 \%$ com algum tipo de irregularidade, dentre as quais: agrotóxicos não permitidos para cultura, acima do LMR, mais de um agrotóxico no mesmo alimento, e até a presença de um agrotóxico banido no Brasil. Dos 23 agrotóxicos identificados no estudo, 10 já estão proibidos em outros países[15]. Além dos riscos para os consumidores, intoxicações agudas e crônicas são reportadas anualmente por agricultores que trabalham diretamente nas lavouras ${ }^{[16]}$.

Em relação aos aspectos ambientais, estudos em áreas com intensa atividade agrícola demonstraram a presença de agrotóxicos em água para o consumo humano, poços subterrâneos, sedimento de lagoas e em amostras de ar e chuva coletados em pátios de escolas ${ }^{[17,18]}$. Palma ${ }^{[19]}$ verificou o potencial cumulativo de resíduos de agrotóxicos no organismo por meio de estudo com nutrizes, comportamento igualmente observado em amostras de leite de vaca[ ${ }^{[20]}$.

O cenário evidencia as constantes violações das dimensões de Segurança Alimentar e Nutricional (SAN) regulamentadas no Artigo 3o da Lei no 11.346/2006 que dispõem sob o direito ao acesso à alimentos de qualidade em quantidades suficientes, "tendo como base práticas alimentares promotoras de saúde que respeitem a diversidade cultural e que sejam ambiental, cultural, econômica e socialmente sustentáveis"'[21].

Sob a perspectiva de abastecimento e das relações de comercialização inseridos na lógica de sistemas alimentares sustentáveis, produtores e consumidores são elementos centrais. O conceito de dietas sustentáveis está alinhado com a definição de sistemas alimentares sustentáveis do Painel de Especialistas da Organização das Nações Unidas para Alimentação e a Agricultura (HLPE) que define a saúde humana e a SAN como elementos chave para a sustentabilidade e vice-versa[22].

\footnotetext{
"Dietas sustentáveis são aquelas com baixo impacto ambiental que contribuem para segurança alimentar e nutricional e vida saudável, para as gerações presentes e futuras. Dietas sustentáveis são protetivas e respeitam a biodiversidade e ecossistemas, culturalmente aceitas, acessíveis, economicamente justas e viáveis; nutricionalmente adequadas; seguras e saudáveis; otimizando recursos humanos e naturais"[23].
} 
A preocupação com a saúde e o meio ambiente, além de sabor e a procura por alimentos produzidos sem o uso de insumos químicos são os principais fatores apontados por consumidores de Porto Alegre para compra de orgânicos ${ }^{[2]}$. McCarthy e Murphy[25] observaram motivações semelhantes em consumidores australianos, identificando frescor dos alimentos, incentivo à produção local, e a perspectiva do bem-estar social. O conhecimento subjetivo foi apontado entre consumidores belgas destacando a importância da informação e educação para influenciar a procura por este tipo de alimento[26].

A percepção dos consumidores em relação ao preço dos alimentos orgânicos frente aos convencionais é citada nestes estudos como sendo mais elevado, o que apesar de não ser um impeditivo, apresenta-se como uma das principais barreiras para o consumo de tais alimentos [24,25,26].

Levando-se em consideração as questões citadas, o presente estudo teve como objetivo comparar os preços de hortaliças provenientes de sistemas de produção convencional e orgânico, tendo como base os preços nos supermercados para o primeiro grupo, e nos supermercados e em canais alternativos de comercialização em Brasilia, DF para os orgânicos.

\section{MATERIAL E MÉTODOS}

No presente estudo foram observados os preços de varejo de hortaliças provenientes dos sistemas convencional e orgânico, produzidas no Distrito Federal e adjacências, em 2 períodos distintos: a primeira em novembro de 2015 e a segunda em abril de 2016. A maioria das hortaliças avaliadas estavam em alta ou média sazonalidade em pelo menos um dos períodos de coleta, representando uma maior estabilidade nos preços ou período de preços baixos ${ }^{[2]]}$

Os preços foram coletados em diferentes canais de comercialização, nas duas ocasiões, contemplando no caso dos orgânicos, os três tipos de certificação vigentes - por auditoria - a mais onerosa , Sistema Participativo de Garantia (SPG) - custos socializados - e Controle Social para Venda Direta sem Certificação - sem custos e sem selo. Os alimentos certificados por auditoria e SPG estavam identificados com o selo de orgânico nas embalagens, enquanto os agricultores que comercializam através do Controle
Social para Venda Direta (sem o selo), estavam portando a Declaração junto ao MAPA conforme determina a legislação.

Para as coletas referentes às hortaliças convencionais e orgânicas, foram visitadas três grandes redes de supermercados concorrentes, sendo uma localizada em região nobre e de alto poder aquisitivo, a segunda com funcionamento 24 horas. localizada perto da Universidade de Brasília, público heterogêneo, e a terceira com características de hipermercado localizada às margens de uma rodovia. Os orgânicos encontrados nos supermercados eram predominantemente certificados por auditoria.

Adicionalmente, foram visitados outros três canais que comercializam orgânicos. No Mercado Orgânico, alimentos certificados por auditoria e por SPG, e no galpão da agricultura familiar (AF), Controle Social para Venda Direta sem Certificação, ambos localizados na Central de Abastecimento de Alimentos (Ceasa/DF). E por fim, o canal "feiras de rua", no qual foram observadas três feiras distintas, localizadas nos bairros asa sul e asa norte, também contendo alimentos certificados por auditoria e por SPG.

As hortaliças as quais foram verificados os preços de varejo foram definidas considerando as mais consumidas segundo a Pesquisa de Orçamentos Familiares (POF) 2008/09[28], acrescidas com as hortaliças disponíveis nos canais conforme a sazonalidade nos períodos das coletas. As análises foram elaboradas para até 25 hortaliças das seguintes variedades: abóbora japonesa, abobrinha italiana, alface crespa, batata, batata doce, berinjela, beterraba, brócolis, cebola, cenoura, chuchu, couve, inhame, jiló, mandioca, maxixe, milho verde, pepino, pimentão "colorido" (vermelho e amarelo), pimentão verde, rabanete, repolho verde, tomate salada, tomate cereja e quiabo.

Buscou-se padronizar ao máximo a variedade das hortaliças para comparações. Este foi um dos limitantes do número amostral do estudo nas comparações, especialmente em relação aos comercializados nos supermercados, razão pela qual foram comparados os preços de 16 alimentos (Figura 1) e não 25 (Figura 2). 
Os preços, em reais ( $\mathrm{R} \$)$, foram registrados em planilhas de maneira direta e na forma com que eram comercializados (ex. g, kg, maço, unidade), sendo posteriormente tabulados em planilha Excel®. Após a coleta, os dados foram padronizados em $\mathrm{kg}$ e unidade para fins comparativos, sendo assim, os alimentos vendidos por peso inferior a um quilo tiveram os valores corrigidos para esta unidade.

A correção foi feita com base na pesagem no memento da coleta. Por exemplo, um pacote contendo três berinjelas com $600 \mathrm{~g}$ de peso era vendido em determinado canal por " $\mathrm{R} \$ 5$ ", aplicou-se regra de três simples para possibilitar as comparações em $\mathrm{kg}$, neste caso, o preço considerado da berinjela seria o do quilo a $\mathrm{R} \$ 8,3$. Nos supermercados, todos os alimentos eram anunciados em $\mathrm{kg}$ ou unidade com o referido preço, dispensando a pesagem.

Os canais observados foram agrupados em quatro categorias: "Supermercados", "Feiras", "Mercado Ceasa" e "Agricultura Familiar (AF)". As análises foram divididas em duas etapas. $\mathrm{Na}$ primeira, foram comparados apenas os preços dos orgânicos em diferentes canais. Para tanto, foi calculada uma média aritmética dos preços de alimentos repetidamente encontrados nos três supermercados, nas três feiras de rua, em três bancas da agricultura familiar, com exceção do Mercado Orgânico da Ceasa que dispunha de apenas um ponto de comercialização.

Para minimizar possíveis distorções na comparação nos diferentes meses pesquisados, foi calculada uma segunda média aritmética após os dois períodos de coleta. Para as hortaliças que estavam disponíveis em apenas um período, foi utilizada a média do mês em que ela foi encontrada. Seguindo os critérios referidos, a Figura 1 demonstra a comparação dos orgânicos entre si. Cestas teóricas contendo 16 alimentos foram estimadas, sendo o fator limitante para o número de comparações os alimentos encontrados no canal "supermercados".

$\mathrm{Na}$ segunda etapa, as hortaliças orgânicas dos três canais foram comparadas com as hortaliças convencionais dos supermercados, representadas na Figura 2. Foi empregada a mesma lógica de coleta e sistematização das médias de preços descrita na primeira etapa. No entanto, o universo de amostras comparadas foi maior, chegando a 25 alimentos. Nesta etapa também foram aplicadas faixas percentuais de diferença de preços, variando desde "equivalente", quando o preço entre o valor no supermercado e no canal comparado não ultrapassou 5\%, até mais de 100\% de diferença no preço. Tomou-se como referencial o preço médio das hortaliças convencionais nos supermercados a partir da seguinte equação: 100 ([Média do preço no supermercado]/[Média de determinado canal] x 100) [29].

\section{RESULTADOS E DISCUSSÃO}

$\mathrm{Na}$ Figura 1, são apresentados os valores médios da soma de 16 hortaliças orgânicas comercializadas nos canais de abastecimento pesquisados. Os dados são referentes à primeira etapa de análises conforme descrito na metodologia, e apresentam a comparação das seguintes variedades: alface crespa, batata, batata doce, berinjela, beterraba, brócolis, cebola, cenoura, chuchu, couve, inhame, milho verde, rabanete, repolho verde, tomate salada e tomate cereja.

O preço da soma total das 16 hortaliças orgânicas comercializadas nos supermercados foi superior a todos os outros canais, chegando a custar mais que o dobro. Os alimentos também foram mais onerosos quando analisados individualmente em praticamente todos os comparativos. As únicas exceções observadas foram a batata e o inhame no Mercado Orgânico da CEASA que apresentaram valor mais elevado.

Figura 1. Preço médio da compra de 16 alimentos orgânicos

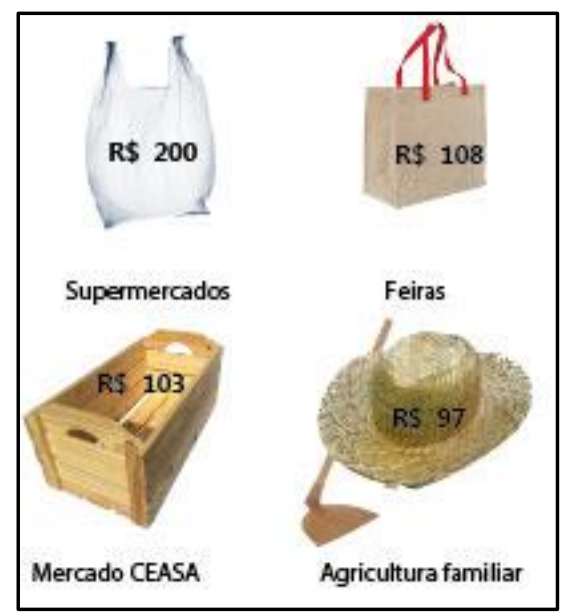

Os alimentos orgânicos comercializados pela agricultura familiar apresentaram preços mais baixos 
tanto na soma coletiva quanto nas comparações individuais. No comparativo direto, alguns alimentos orgânicos do canal supermercados chegaram a custar mais do que o triplo do preço em relação ao mesmo alimento da agricultura familiar, como no caso do tomate cereja, rabanete e chuchu.

Os dois canais que se posicionam nos extremos em relação aos preços, também apresentam características antagônicas no que diz respeito a proximidade entre produtor e consumidor final e a forma de certificação. Enquanto na agricultura familiar a Venda e certificação são feitas de maneira Direta através do Controle Social, nos supermercados os alimentos comercializados possuem majoritariamente $\mathrm{o}$ selo de certificação por auditoria, a mais onerosa e com um maior grau de exigências e encargos.

Os preços praticados nos supermercados se mostraram substancialmente superiores em relação aos demais locais, sugerindo que o nível de segmentação da cadeia produtiva e de socialização dos encargos relativos ao processo de certificação influenciam no preço final das hortaliças.

A presença do selo orgânico auxilia os consumidores na identificação e garantia destes alimentos, mas não é um fator preponderante para a compra. Estudo sobre o perfil dos consumidores de orgânicos do Distrito Federal demonstra que a presença do selo é o quinto item em uma lista de sete características que influenciam a compra ${ }^{[11]}$. No tocante a confiabilidade, a relação entre produtor e consumidor assim como o porte da Declaração para Venda Direta e presença do selo foram considerados adequados por frequentadores de feiras ecológicas em Manaus ${ }^{[30]}$.

Os canais "feiras" e "mercado ceasa", apresentaram comportamento semelhante em relação aos preços praticados e ao tipo de certificação. Em relação a apresentação, semelhanças foram observadas entre os dois canais e os orgânicos dos supermercados. Os alimentos ficam expostos em embalagens, diferentemente do canal agricultura familiar onde os alimentos são expostos majoritariamente a granel, característica também observada na forma de venda das hortaliças convencionais nos supermercados. $\mathrm{O}$ custo adicional com embalagens também compõe o preço final do alimento.
Outro fator relevante, é que a variedade e a oferta de alimentos orgânicos encontrados nos supermercados foram menores em comparação com os outros canais. Tal fato pode ser justificado pela necessidade de oferta continua e padronizada para venda nos supermercados, ao passo que em outros canais existe uma maior flexibilização em relação a oferta. Outro motivo pode estar relacionado com a participação de um número maior de agricultores em espaços destinados exclusivamente a venda de alimentos orgânicos e agroecológicos, aumentando o espectro de variedades ofertadas.

As diferenças de preço observadas nos quatro canais indicam que são incompletas as afirmações sobre o preço de alimentos orgânicos que não considerem a pluralidade dos canais de abastecimento. O preço elevado dos orgânicos em supermercados pode justificar a percepção dos consumidores de que estes alimentos são financeiramente inviáveis.

Em relação a composição dos preços, cabe destacar que outros aspectos que não sejam necessariamente a qualidade do produto influenciam no preço final. Tais como a manutenção da infraestrutura e definição das margens de lucro entre o preço pago ao produtor e o final repassado aos consumidores praticados nos supermercados em comparação a outros canais alternativos por exemplo.

Estudo implementado em Ilhéus (BA) constatou que as mídias tradicionais (reportagens, jornais e revistas) são os principais meios de divulgação de alimentos orgânicos ${ }^{[11]}$. Tais mídias, divulgam predominantemente informações relativas ao preço dos orgânicos tendo os supermercados como referência, podendo distorcer uma compreensão ampliada dos consumidores sobre o tema ${ }^{[32,33]}$. Por outro lado, veículos mais democráticos identificam outros determinantes que influenciam nos preços e locais de comercialização dos orgânicos, aumentando o escopo de informações ${ }^{[3,35]}$.

Informações sobre a diversidade de canais de abastecimento e grupos de consumo deveriam ser apresentadas aos consumidores. De acordo com o Mapa de Feiras Orgânicas idealizado pelo Instituto Brasileiro de Defesa do Consumidor (Idec), existem atualmente 740 iniciativas que comercializam orgânicos em canais alternativos no Brasil[36]. Além das 
possibilidades de locais de compra, deveriam ser priorizadas informações sobre as diferenças de preços destes canais em relação aos supermercados assim como das dimensões de sustentabilidade contempladas na produção orgânica e agroecológica.

Posterior a análise dos orgânicos entre si, foram comparados os preços das hortaliças orgânicas dos três canais alternativos em relação às hortaliças convencionais nos supermercados. Tomando-se o supermercado como base, foram comparadas 25 hortaliças de acordo com a disponibilidade encontrada, com exceção do canal feiras onde não foi encontrado jiló e do Mercado da Ceasa onde não foram encontrados abóbora, abobrinha, pimentão "colorido" e quiabo nos dias da coleta. A Figura 2 apresenta as diferenças de preços em faixas percentuais conforme detalhado na metodologia.

Figura 2. Diferença de preços das hortaliças orgânicas em distintos canais em relação ao preço das convencionais nos supermercados

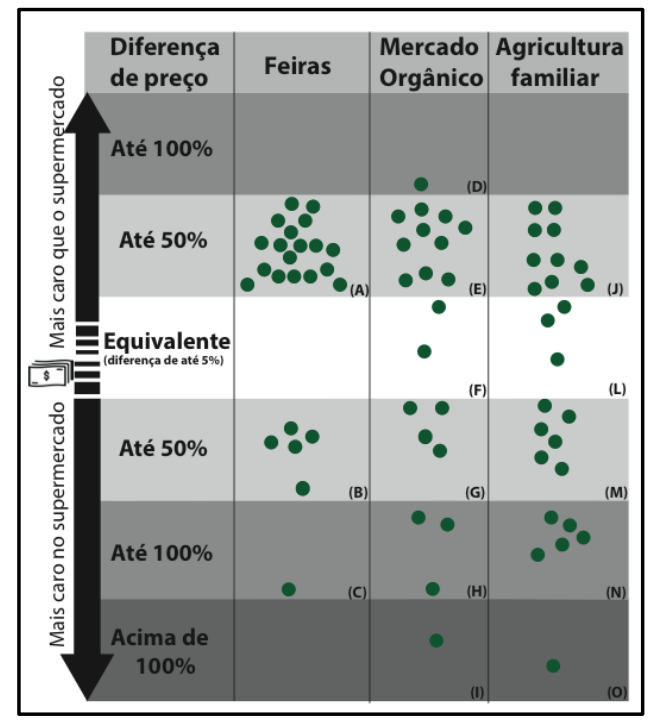

Legenda: (A) Abóbora, abobrinha, alface, batata doce, batata, berinjela, cebola, cenoura, chuchu, couve, milho, pepino, pimentão colorido, pimentão verde, rabanete, repolho, tomate, quiabo; (B) Beterraba, brócolis, inhame, mandioca, maxixe; (C) Tomate cereja; (D) Pepino; (E) Batata doce, batata, berinjela, beterraba, cebola, chuchu, couve, milho, rabanete, tomate; (F) Alface, pimentão verde; $(\mathrm{G})$ Cenoura, inhame, jiló, repolho; $(\mathrm{H})$ Brócolis, mandioca, maxixe; (I) Tomate cereja; (J) Abóbora, batata doce, batata, berinjela, cebola, cenoura, chuchu, milho, rabanete, tomate; (L) Pepino, pimentão colorido, inhame; (M) Abobrinha, alface, beterraba, couve, repolho, quiabo; $(\mathrm{N})$ Brócolis, jiló, mandioca, maxixe, pimentão verde; $(\mathrm{O})$ Tomate cereja.

O quadrante superior da Figura concentrou a maior dispersão de alimentos, revelando que as hortaliças de produção convencional apresentaram os menores preços no comparativo geral. Fato observado em $56 \%(n=39)$ dos casos, enquanto as orgânicas tiveram preços mais baixos em $37 \%(n=26)$. Os preços foram considerados equivalentes em $7 \%(n=5)$ das comparações. Entretanto, uma análise mais detalhada comparativa da média dos supermercados com cada canal, representado nas colunas da figura, permite uma melhor compreensão.

As hortaliças orgânicas da agricultura familiar se mostraram novamente as mais baratas mesmo quando confrontadas com as convencionais no supermercado. Dos 25 alimentos avaliados, a maior parte $48 \%(n=12)$, apresentou um preço mais baixo e $12 \% \quad(\mathrm{n}=3$ ) ficou na faixa "equivalente" (diferença $<5 \%$ ). Este é um indicativo contundente de que a modalidade familiar de base agroecológica pode ofertar alimentos orgânicos a preços equivalentes e até mesmo mais baratos do que a agricultura convencional dependendo do canal de abastecimento.

O Mercado Orgânico da CEASA ao ser confrontado com as hortaliças de produção convencional dos supermercados, demonstrou que mesmo o preço de uma maior parte do conjunto dos orgânicos $52 \%(\mathrm{n}=11)$, neste caso, custar mais caro, os alimentos apresentaram preços competitivos, sendo mais baratos em 38\% $(\mathrm{n}=8)$ e equivalentes em 10\% $(\mathrm{n}=2)$ das comparações.

Já o canal "feiras", se mostrou o menos competitivo no comparativo individual de preços, ainda que todos os $75 \%(n=18)$ tenham ficado na faixa de até $50 \%$ mais caros. No canal "feiras", assim como no "mercado orgânico", os alimentos apresentaram majoritariamente o selo de certificação através do SPG, e alguns também por auditoria.

Cabe ressaltar que no comparativo geral, dos 31 alimentos orgânicos que apresentaram preços mais elevados, apenas um ultrapassou a faixa de até $50 \%$ de incremento, enquanto que dos 26 alimentos da agricultura convencional custando mais caros, 11 se concentraram nas faixas maior que $50 \%$, chegando a custar mais que $100 \%$ do preço dos orgânicos. Tal fato sugere que mesmo que determinado canal orgânico apresente alimentos mais caros, as diferenças de preços não chegariam a inviabilizar a compra. 
Deve-se destacar que diferentes elementos como custos com a produção, insumos, mão de obra, logística, embalagem, certificação e outros fatores como sazonalidade, demanda e políticas de subsídios e incentivos interferem no preço final de um alimento.

Enquanto a produção de base agroecológica pressupõe uma produção de alimentos ambientalmente sustentável e formas de comercialização justas do ponto de vista socioeconômico, os custos com externalidades negativas ${ }^{[37,38]}$, advindas do uso de agrotóxicos por exemplo, não são contabilizados no preço final dos alimentos de produção convencional, tornando desigual uma comparação estritamente baseada no preço final de comercialização. Tais custos e agravos são socializados entre o meio ambiente e a saúde da população e dos agricultores, ao passo que os preços mais baratos muitas vezes são resultantes de impactos negativos gerados ao longo das etapas do sistema alimentar.

As análises da Figura 2 demonstram que mesmo que os alimentos da agricultura convencional custem menos no comparativo geral, os alimentos orgânicos podem ser mais baratos dependendo do canal de comercialização. Além do fator preço por si só ser competitivo, são evidentes os benefícios relativos à segurança alimentar e nutricional dos consumidores e agricultores, à proteção da sociobiodiversidade e das demais dimensões intrínsecas aos sistemas alimentares sustentáveis refletidos na produção de base ecológica. Para tanto, é imprescindível que a produção orgânica e agroecológica seja capaz de ofertar alimentos em quantidade e a preços acessíveis para a população brasileira, se afirmando como uma alternativa ao modelo do agronegócio.

\section{CONCLUSÃO}

O nível de aproximação entre agricultores e consumidores finais, assim como o tipo de certificação parecem influenciar no preço final das hortaliças orgânicas. Canais alternativos de abastecimento se apresentam como os principais ambientes para oferta de alimentos saudáveis e sustentáveis podendo inclusive apresentar preços mais competitivos do que os convencionais dependendo do local.

Assim, estratégias que priorizem a consolidação destes espaços e o fortalecimento de políticas públicas que ampliem a produção e tornem alimentos orgânicos mais baratos e acessíveis em consonância com as dimensões de Segurança Alimentar e Nutricional são essenciais.

Sugere-se que as campanhas de educação e informação aos consumidores tenham como foco os canais alternativos e auxiliem os agricultores inseridos em sistemas orgânicos e agroecológicos de produção. A veiculação de informações pelas mídias tradicionais deve considerar a pluralidade dos canais que comercializam alimentos orgânicos, e não apenas os supermercados. Além de informações sobre o preço final, também devem ser levadas aos consumidores informações sobre os fatores que influenciam no preço dos alimentos de produção convencional ou orgânica e agroecológica, assim como os impactos causados por cada sistema.

As observações do estudo refletem os resultados localmente obtidos. Não obstante, outros trabalhos que superem as limitações e avancem para uma compreensão mais aprofundada dos indicadores e determinantes se fazem necessários.

\section{REFERÊNCIAS}

[1] Leu A. Consolidated annual report of IFOAM: Organics International (2016) [Internet]. Germany: Head Office Charles-deGaulle-Str; 2016 [acesso em 16 dez 2016]. Disponível em: http://www.ifoam.bio/sites/default/files/annual_report_2016.pdf

[2] Ormond JG, Paula SR, Faveret PS, Rocha LT. Agricultura orgânica: quando o passado é futuro. BNDES Setorial [Internet], 2002 [acesso em 15 jan 2014]; 15:3-34. Disponível em: https://web.bndes.net/bib/jspui/handle/1408/2479

[3] Brasil. Mais orgânicos na mesa do brasileiro em 2017 [Internet]. 2017 [acesso em 18 jan 2017]. Disponível em: http://www.mda.gov.br

[4] Câmara Interministerial de Agroecologia e Produção Orgânica. Plano Nacional de Agroecologia e Produção Orgânica. Brasilia (DF); 2013.

[5] Brasil. Decreto no 7.794, de 20 de agosto de 2012. Institui a Política Nacional de Agroecologia e Produção Orgânica. Diário Oficial da União. 21 ago 2012.

[6] Wezel A., Bellon S, Dore T, Francis C, Vallod D, David C. Agroecology as a science, a movement and a practice: a review. Paris: INRA; 2009. 
[7] ABA. Estatuto da Associação Brasileira de Agroecologia - ABA. Rio de Janeiro: ABA; 2015.

[8] Brasil. Decreto no 6.323, de 27 de dezembro de 2007. Regulamenta a Lei no 10.831, de 23 de dezembro de 2003, que dispõe sobre a agricultura orgânica, e dá outras providências. Diário Oficial da União. 28 dez 2007.

[9] Brasil. Lei no 10.831, de 23 de dezembro de 2003. Dispõe sobre a agricultura orgânica e dá outras providências. Diário Oficial da União. 24 dez 2003.

[10] Companhia de Planejamento do Distrito Federal. O Mercado de Produtos Orgânicos: Mecanismos de Controle [Internet], 2015 [acesso em 15 jul 2015]. Disponível em: http://www.codeplan.df.gov.br/images/CODEPLAN/PDF/pes quisa_socioeconomica/politicas_sociais/2015/Mercado_Produtos _Organicos_2015.pdf

[11] Almeida IL. Caracterização de consumidores, tendência de mercado e estratégias para o crescimento do segmento de hortaliças no Distrito Federal e Entorno [dissertação]. Brasília: Universidade de Brasília; 2012.

[12] Emater. Informativo da produção agrícola do Distrito Federal ano safra: 2009/2010. Empresa de Assistência Técnica e Extensão Rural. Brasilia (DF): Emater; 2010.

[13] Carneiro FF, Pignati W, Rigotto RM, Augusto LG, Rizzolo A, Faria NM. et al. Segurança alimentar e nutricional e saúde. In: Carneiro FF (org). Rio de Janeiro: ABRASCO; 2012. p. 46-89.

[14] Agência Nacional de Vigilância Sanitária. Programa de Análise de Resíduos de Agrotóxicos em Alimentos (PARA): Relatório das análises de amostras monitoradas no período de 2013 a 2015. Brasília (DF): ANVISA; 2016.

[15] Greenpeace. Segura este abacaxi! Os agrotóxicos que vão parar na sua mesa [Internet]. 2017 [acesso em 15 out 2017]. Disponível em: http://greenpeace.org.br/agricultura/segura-este-abacaxi.pdf

[16] Faria NM, Fassa AG, Facchini LA. Intoxicação por agrotóxicos no Brasil: os sistemas oficiais de informação e desafios para realização de estudos epidemiológicos. Ciênc. Saúde Coletiva [Internet]. 2007 [acesso em 2015 nov 8]; 12(1):1225-38. Disponível em: http://www.redalyc.org

[17] Marinho AM. Contextos e contornos da modernização agrícola em municípios do Baixo Jaguaribe - CE: o espelho do (des)envolvimento e seus reflexos na saúde, trabalho e ambiente [dissertação]. São Paulo: Universidade de São Paulo; 2010.

[18] Pignati WA, Machado JH, Cabral JF. Acidente rural ampliado: o caso das "chuvas" de agrotóxicos sobre a cidade de Lucas do Rio Verde. Ciênc. Saúde Coletiva [Internet]. 2007 [acesso em 2015 nov 8]; 12(1):105-140. http://dx.doi.org/10.1590/S141381232007000100014.
[19] Palma DC. Agrotóxicos em leite humano de mães residentes em Lucas do Rio Verde, MT [dissertação]. Cuiabá: Universidade Federal do Mato Grosso; 2011.

[20] Nero LA, Mattos MR, Beloti V, Barros MA, Netto DP, Franco BD. Organofosforados e carbamatos no leite produzido em quatro regiões leiteiras no Brasil: ocorrência e ação sobre Listeriamonocytogenes e Salmonella spp. Ciênc. Tecnol. Aliment. 2007;27(1):201-204.

[21] Brasil. Lei no 11.346, de 15 de setembro de 2006. Cria o Sistema Nacional de Segurança Alimentar e Nutricional - SISAN com vistas em assegurar o direito humano à alimentação adequada e dá outras providências. Diário Oficial da União. 28 set 2006.

[22] HLPE. Food losses and waste in the context of sustainable food systems. A report by the High Level Panel of Experts on Food Security and Nutrition of the Committee on World Food Security [Internet]. 2014 [acesso em 15 out 2017]. Disponível em: http://www.fao.org/3/a-i3901e.pdf

[23] FAO. Sustainable diets and biodiversity: directions and solutions for policy, research and action. Rome: FAO; 2012.

[24] Hoppe A, Vieira LM, Barcellos MD. Consumer behaviour towards organic food in Porto Alegre: an application of the theory of planned behaviour. Rev. Econ. Sociol. Rural [Internet]. 2013 [acesso em 2014 mar 10];51(1):69-90. Disponível em: http://dx.doi.org/10.1590/S010320032013000100004.

[25] McCarthy B, Murphy L. Who's buying organic food and why? Political consumerism, demographic characteristics and motivations of consumers in North Queensland. Tour. \& Manag. Studies. 2013;9(1):72-79.

[26] Pieniak Z, Aertsens J, Verbeke W. Subjective and objective knowledge as determinants of organic vegetables consumption. Elsevier. 2010;21:581-588.

[27] Ceasa. Calendário de comercialização de hortaliças. Centrais de Abastecimento do Distrito Federal, DF [Internet]. 2015 [acesso em 10 nov 2015]. Disponível em: http://www.ceasa.df.gov.br

[28] Instituto Brasileiro de Geografia e Estatística. Pesquisa de orçamentos familiares 2008-2009: Análise do consumo alimentar pessoal no Brasil. Rio de Janeiro: IBGE; 2011.

[29] Instituto Terra Mater, Instituto Kairós. Produtos sem veneno são sempre mais caros? [Internet]. 2016 [acesso em 10 jan 2017]. Disponível em: http://institutokairos.net

[30] Santiago OA, Gentil DO. Estudo comparativo da comercialização de hortaliças orgânicas e convencionais em Manaus, Amazonas. Revista Brasileira de Agroecologia. 2014;9(3):124-139. 
[31] Gomes AS, Noqueira RB, Rosado PL. Determinantes da demanda de hortaliças orgânicas em Ilhéus. Conj. \& Planej. 2009;162:66-71.

[32] Santos G. Preço alto ainda limita consumo de orgânicos; diferença chega a 270\% [Internet]. Folha de São Paulo. 2015 jul 05 [acesso em 15 jul 2015]. Disponível em: http://www1.folha.uol.com.br

[33] Marin T, Ferraz Y. Produtos orgânicos custam até $652 \%$ mais caro [Internet]. Diário do Grande ABC. 2013 jul 10 [acesso em 20 jul 2013]. Disponível em: http://www.dgabc.com.br

[34] Preiss PV. Comida orgânica é mais cara: questionando o mito [Internet]. Porto Alegre: SlowFood Brasil; 2013 [acesso em 15 abr 2014]. Disponível em: https://www.slowfoodbrasil.com

[35] Redação. Comércio honesto vende produtos orgânicos pelo preço do produtor [Internet]. São Paulo: Catraca Livre; 2016 [acesso em 15 mai 2016]. Disponível em: https://catracalivre.com.br

[36] Instituto Brasileiro de Defesa do Consumidor. Mapa de feiras orgânicas [Internet]. São Paulo: Idec; 2015 [acesso em 15 out 2015]. Disponível em: https:/ / feirasorganicas.org.br

[37] Soares WL, Porto MF. Atividade agrícola e externalidade ambiental: uma análise a partir do uso de agrotóxicos no cerrado brasileiro. Ciênc. Saúde Coletiva [Internet]. 2007 [acesso em 2017 out 05];12(1):131-143. Disponível http://dx.doi.org/10.1590/S1413-81232007000100016.

[38] Soares WL, Porto MF. Estimating the social cost of pesticide use: An assessment from acute poisoning in Brazil: challages to sustainability and environmental justice. Ciênc. Saúde Coletiva [Internet]. 2009 [acesso em 2017 out 05];14(6):1983-1994. Disponível em: http://dx.doi.org/10.1590/S141381232009000600006 